\title{
QUANTIFYING PERCEPTIONS OVER THE STUDENTS' MAIN REWARDS IN HIGHER EDUCATION: MOTIVATIONAL THEORIES VERSUS SPECIFIC CONSTRUCTS
}

\author{
Shahrazad Hadad \\ Bucharest University of Economic Studies \\ Bucharest, Romania \\ E-mail: hadadshahrazad07@stud.ase.ro \\ Razvan Bucur \\ Bucharest University of Economic Studies \\ Bucharest, Romania \\ E-mail: bucur.razvan@ymail.com \\ Adriana Agapie \\ Faculty for Business Administration \\ Bucharest University of Economic Studies \\ Institute for Economic Forecasting \\ Bucharest, Romania \\ E-mail: adriana.agapie@yahoo.com
}

\begin{abstract}
For a carefully designed hierarchy, if it makes sense for explaining the alternatives involved, we expect that variations in the perceived importance of the alternatives will not be significant. That, if checked, constitutes an argument of the robustness of the AHP method in general and in particular on the motivational theories in education. The paper presents and compares the results of two experiments that were conducted in a Romanian university. Two hierarchies on what motivates a business student were designed: the first one was constructed through consensus by students, while the second one was inspired from Adamus's (2013) AHP model on the motivational theories in education. In the context of the particularly chosen criteria and sub-criteria, the results indicate that students care more about the overall rewarding goal of getting a diploma than about specific intermediary steps in achieving it, as for example getting good grades.
\end{abstract}

Keywords: student motivation, AHP, higher education, consistency

\section{Introduction}

Being a teacher is assumed and confirmed to be among the most self-reinforcing rewarding professions. Being a student is discontinuously mirroring the intrinsic motivation of the teacher. 
There are four main instruments specifically mentioned in regulations designed to reflect and quantify the degree of students' motivation in learning. In an arbitrary order, these are tuition, diploma, scholarships and grades. The efficiency in terms of motivation of each of these instruments is subjectively perceived by each student; yet the mainstream opinion of their overall efficiency changes annually depending on the evolutions on the labor market and on the changes in regulations regarding education. The fact is that diploma can act as a trigger to motivation because it is the tangible "asset" the students get when graduating. Acquiring the diploma/degree is conditioned by grades and by passing each subject's corresponding exam. Tuition refers to the amount of money the students pay and it is in influenced by grades in the sense that if students get an average grade of 8 (on a scale from 1-10), they might lose the state grant and they might have to pay the tuition; also, those that are currently paying the tuition, if they get good grades, they might have the chance of benefitting from a state grant - the classification of students (tax-payers and non-payers) changes every year based on the average points they get. Scholarships, could also lead to an increased motivation lastly, but not least, due to the level of poverty.

The next experiment was conducted along the introductory two courses of Business Decision Processes. Students were asked to design a hierarchy having on top the question What motivates a business administration student?, and on the last layer the four main formal rewards as presented below. The criteria and sub-criteria together with the corresponding connections were decided through consensus after three-week seminar debates. The results and also the structuring of the hierarchy will come up as a surprise to anyone who is curious in this respect.

Alternatively, another hierarchy with the same top and last layer, as the previous one, was constructed based on the research on motivational theories applied in education, conducted by Adamus (2013). This paper aims at comparing the differences in the priority vectors corresponding to the two different hierarchies built in this context: the particular one derived by students and the one constructed according to motivational theories as in Adamus. These differences are regarded as a measure of the hierarchy's dependence of the particular alternatives considered and also as a way of validating the simpler Adamus's hierarchy.

\section{Brief overview on students' motivation in higher education}

According to Adamus (2013, p.35), "most modern views on motivation of students emphasize its cognitive features and purpose orientation." Adamus (2013) used AHP to identify and compare motivators of school directors with respect to school management, teachers with respect to work at school, pupils with respect to studying at school and parents with respect to a school selected by pupils; his main purpose was to examine the impact of transformation changes and the impact of educational reform on the system of managing upper secondary schools with special attention being given to motivation in the management process.

We happily noticed the coincidence of the students' choice for the criteria as Saaty's and Shang's (2011) choice of the criteria in "An innovative orders-of-magnitude approach to AHP-based multi-criteria decision making: Prioritizing divergent intangible humane acts", as being the five levels in Maslow's hierarchy The researchers developed their 
IJAHP Article: Mu, Saaty/A Style Guide for Paper Proposals To Be Submitted to the International Symposium of the Analytic Hierarchy Process 2014, Washington D.C., U.S.A.

hierarchy with a twist on Maslow's approach therefore they selected as criteria and subcriteria: physical [food, clothing, shelter, medical], emotional [esteem, selfactualization], social [safety needs, belonging needs] and environmental[water, air, waste, nature]. They concluded that in terms of business and education, the proposed AHP model could be applied to the evaluation of schools, supermarkets, and fast food chain stores, whose performance involves tangible and intangible criteria.

According to Hadad (2012), business administration students (FABIZ) may also be motivated by the brain dominance of the teacher reflected in the way they teach and evaluate.

\section{Research}

The aim of the paper is to prove that no matter the hierarchy constructed, if it makes sense and it is carefully designed for explaining the alternatives, we expect that variations in the perceived importance will not be significant.

After several debates, the students decided to organize the criteria - the second layer - of the hierarchy based on Maslow's pyramid of needs (physiological, security, social, selfesteem and self-actualization). For each criterion, there have been identified in between two to three sub-criteria, such as: Need for accommodation, Need for intimacy, Nice environment, Certainty, Reputation, Networking, Achievement, Sense of career, Passion, Creativity Stimulation, Becoming a mentor - the third layer. And, at the final level, they decided for the next alternatives: Diploma, Tuition, Grades, and Scholarships (Fig.1.).

Figure 1 . Hierarchy designed by students

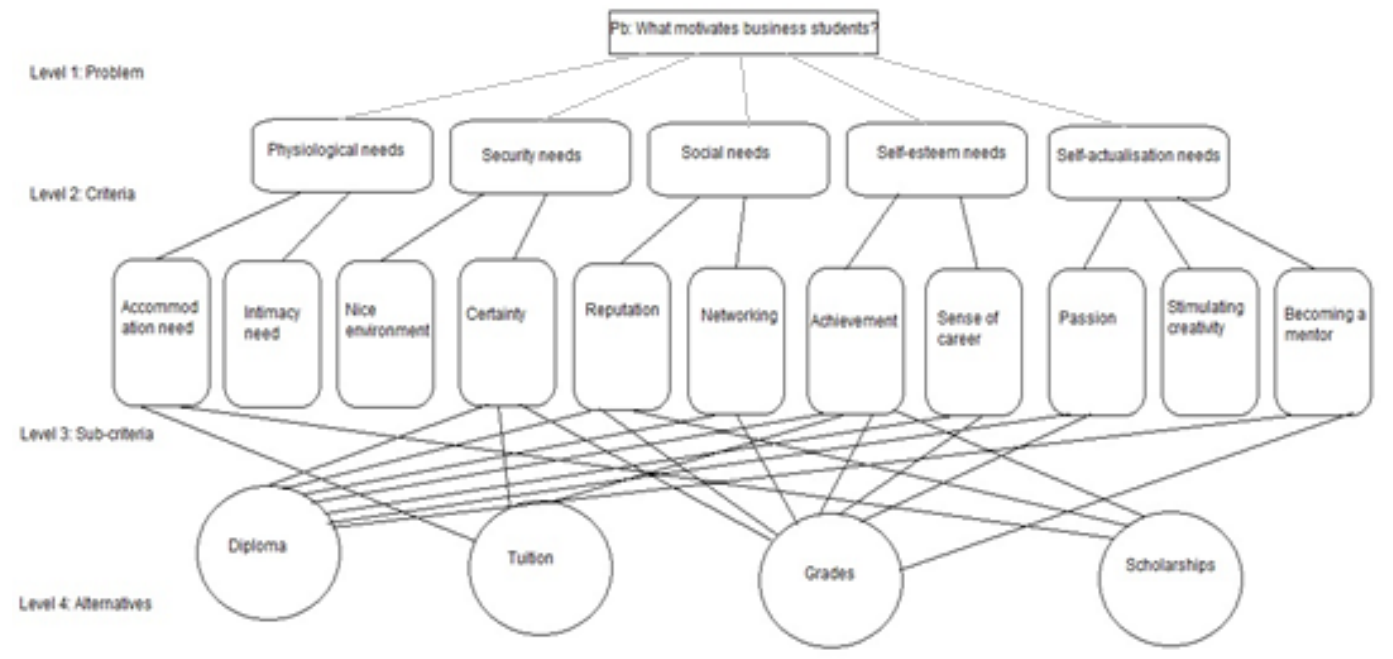

At the same time, we designed the second hierarchy based on Adamus (2013): At the top level it contained the problem: what motivates business students? The second layer enlisted the criteria: Teaching conditions (environment, facilities), Teacher-student relationship (refers to the behavior the teacher manifests towards the student), Studentteacher relationship (reflects the behavior the student manifests towards the teacher) and Relationship with friends. On the last layer we placed as alternatives the following: Diploma, Tuition, Grades, and Scholarships (Fig.2.). 
IJAHP Article: Mu, Saaty/A Style Guide for Paper Proposals To Be Submitted to the International Symposium of the Analytic Hierarchy Process 2014, Washington D.C., U.S.A.

Figure 2. Hierarchy designed based on Adamus (2013)

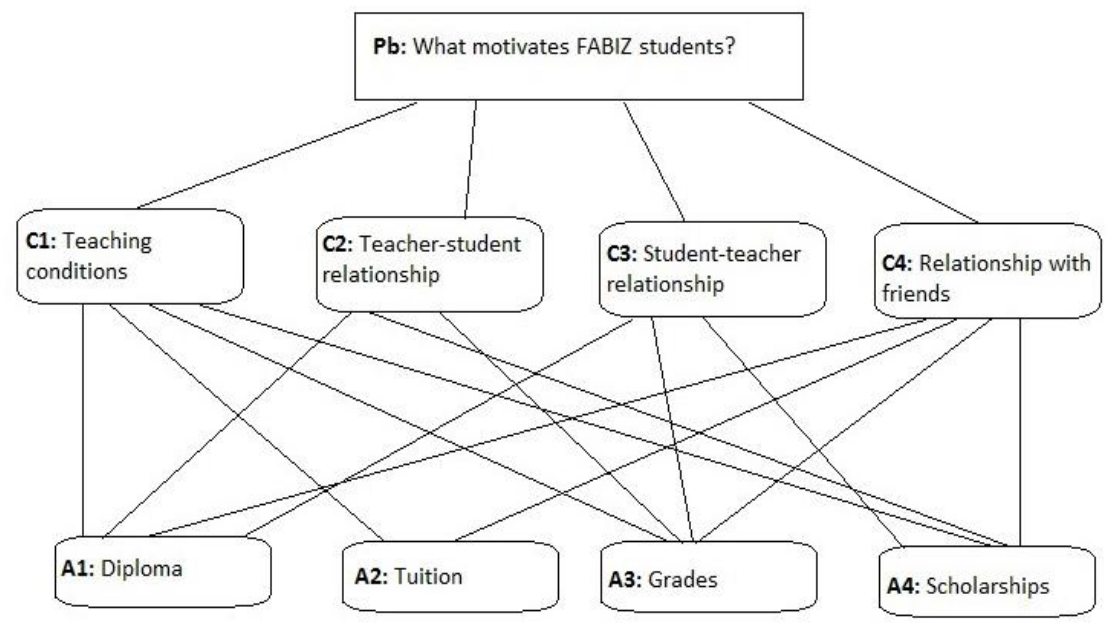

Based on these two hierarchies, we formulated two distinct surveys compounded of pairwise comparison questions on each hierarchical level in relation to the joint criterion located at the immediately upper-level. Thirty five students were asked to individually fill in both of the questionnaires associated to each of the previously identified hierarchies.

\section{Results and analysis}

Ten individual responses to the comparative questions according to the specific hierarchy developed with the Business Administration Faculty students, regardless the consistency indices associated with the decision matrices are reported in Table 4.1.

Table 4.1.

\begin{tabular}{|l|r|r|r|r|}
\hline & A1 (Diploma) & A2 (Tuition) & A3 (Grades) & A4( Scholarships) \\
\hline Resp 1 & 0.55961559 & 0.014310566 & 0.13380669 & 0.28900259 \\
\hline Resp 2 & 0.43910435 & 0.094957846 & 0.35709176 & 0.10884604 \\
\hline Resp 3 & 0.87814733 & 0.031177254 & 0.041774134 & 0.048092556 \\
\hline Resp 4 & 0.82955952 & 0.00565273 & 0.116452 & 0.048335755 \\
\hline Resp 5 & 0.84971883 & 0.002762306 & 0.07988976 & 0.068201913 \\
\hline Resp 6 & 0.78592068 & 0.043067609 & 0.1125713 & 0.05891018 \\
\hline Resp 7 & 0.43678865 & 0.038830828 & 0.12727905 & 0.39710147 \\
\hline Resp 8 & 0.85992577 & 0.037218916 & 0.06718346 & 0.035671859 \\
\hline Resp 9 & 0.76361276 & 0.14463347 & 0.057769435 & 0.033984328 \\
\hline Resp 10 & 0.40832841 & 0.030841579 & 0.47436243 & 0.086467581 \\
\hline MEAN & 0.681072189 & 0.04434531 & 0.156818002 & 0.117461427 \\
\hline STDEV & 0.196210573 & 0.043698802 & 0.142568234 & 0.123721405 \\
\hline
\end{tabular}

The last two lines in the above table indicate the mean among the ten respondents' correspondent priority weights and the standard deviation. Standard deviation is interpreted as a measure of the degree of subjectivity associated with the mean value among the ten respondents. 
IJAHP Article: Mu, Saaty/A Style Guide for Paper Proposals To Be Submitted to the International Symposium of the Analytic Hierarchy Process 2014, Washington D.C., U.S.A.

Thus, the order of preferences among the alternatives is listed in Table 4.2 below. In the second line is the descending order of the standard deviations among the four alternatives.

Table 4.2.

\begin{tabular}{|l|l|l|l|}
\hline MEAN & & & \\
\hline A1 (Diploma) & A3 (Grades) & A4 (Scholarship) & A2 (Tuition) \\
\hline STDEV & & & \\
\hline A1 & A3 & A4 & A2 \\
\hline
\end{tabular}

One can observe that in the context of the hierarchy built and evaluated by the students, the higher the associated importance to the reward considered, the higher the degree of subjectivity among the respondents in assessing the importance of that reward.

When every decision matrix was improved in terms of consistency according to the procedure indicated in Benitez et al. (2011) and the corresponding synthetized priority vectors were recalculated together with the mean and standard deviation along the ten respondents, it was found that the results were not significantly different.

Thus, for a comparison with the results in Table 4.1, the results having all the decision matrices perfectly consistent, along the ten respondents are presented in Table 4.3.

Table 4.3

\begin{tabular}{|l|r|r|r|r|}
\hline & A1 & A2 & \multicolumn{1}{l|}{ A3 } & A4 \\
\hline Resp 1 & 0.545412 & 0.017575 & 0.15644 & 0.283837 \\
\hline Resp 2 & 0.399407 & 0.112927 & 0.339 & 0.148667 \\
\hline Resp 3 & 0.882202 & 0.030216 & 0.042583 & 0.045808 \\
\hline Resp 4 & 0.828732 & 0.005788 & 0.116101 & 0.049378 \\
\hline Resp 5 & 0.849946 & 0.002804 & 0.080098 & 0.067716 \\
\hline Resp 6 & 0.779829 & 0.050406 & 0.110041 & 0.060283 \\
\hline Resp 7 & 0.426467 & 0.037299 & 0.127151 & 0.409084 \\
\hline Resp 8 & 0.859218 & 0.038036 & 0.067459 & 0.035287 \\
\hline Resp 9 & 0.754671 & 0.137286 & 0.072776 & 0.035267 \\
\hline Resp 10 & 0.412649 & 0.025075 & 0.467899 & 0.094377 \\
\hline MEAN & 0.673853 & 0.045741 & 0.157955 & 0.12297 \\
\hline STDEV & 0.203244 & 0.044657 & 0.136893 & 0.126029 \\
\hline
\end{tabular}

Obviously, results in Table 4.2 for the case in which all the decision matrices are consistent, are not changed.

For the hierarchy designed having the same as before four alternative rewards according to the Adamus's motivational theory in education, the results for the ten respondents when all the decision matrices were improved in terms of consistency are presented in Table 4.4 below. 
IJAHP Article: Mu, Saaty/A Style Guide for Paper Proposals To Be Submitted to the International Symposium of the Analytic Hierarchy Process 2014, Washington D.C., U.S.A.

Table 4.4.

\begin{tabular}{|l|r|r|r|r|}
\hline & A1 (Diploma) & A2 (Tuition) & A3 (Grades) & A4( Scholarships) \\
\hline Resp 1 & 0.40538849 & 0.062864663 & 0.31734653 & 0.21440032 \\
\hline Resp 2 & 0.20959863 & 0.033154971 & 0.70810875 & 0.049137647 \\
\hline Resp 3 & 0.56789254 & 0.051097297 & 0.27936721 & 0.10164296 \\
\hline Resp 4 & 0.11974892 & 0.027663653 & 0.1659056 & 0.68668182 \\
\hline Resp 5 & 0.30179663 & 0.009170089 & 0.58360093 & 0.10543235 \\
\hline Resp 6 & 0.20173897 & 0.11374062 & 0.58974946 & 0.094770959 \\
\hline Resp 7 & 0.31789868 & 0.055429332 & 0.4619694 & 0.1647025 \\
\hline Resp 8 & 0.046725166 & 0.25305659 & 0.42095167 & 0.27926657 \\
\hline Resp 9 & 0.34712433 & 0.026787628 & 0.29046565 & 0.33562239 \\
\hline Resp 10 & 0.20258064 & 0.046264569 & 0.42558765 & 0.32556714 \\
\hline MEAN & 0.2720493 & 0.067922941 & 0.424305285 & 0.235722466 \\
\hline STDEV & 0.14965211 & 0.070931285 & 0.167283335 & 0.188103106 \\
\hline
\end{tabular}

The correspondent order of preferences together with the associated descending order of the standard deviations, as inferred from the previous table is below, are presented in Table 4.5.

Table 4.5

\begin{tabular}{|l|l|l|l|}
\hline MEAN & & & \\
\hline A3 (Grades) & A1 (Diploma) & A4 (Scholarship) & A2 (Tuition) \\
\hline STDEV & & & \\
\hline A4 & A3 & A1 & A2 \\
\hline
\end{tabular}

\section{Reflection}

It can thus be overall observed that there is a rank reversal in the importance granted to the Grades (A3) and Diploma (A1) rewards in the context of the two hierarchies considered, while the order of preferences among the other two motivational tools, Scholarship (A4) and Tuition (A2) is unchanged. Also, the overall importance of the Grades and Diploma cumulated; in the case of Adamus's hierarchy accounts for 70\% while in the case of the specific hierarchy designed by the students is $80 \%$. Results are still, close. Achieving a diploma can be regarded as a motivational instrument on a long term horizon, while grades are usually regarded as intermediary steps in achieving this long-term goal. This interpretation is consistent with the numerical findings following the synthetized motivational theories in education according to Adamus. On the other hand, it appears that students, in the context of the criteria and sub-criteria particularly considered, care more about the overall rewarding goal of acquiring a Diploma than about the particular steps like getting good grades.

\section{Acknowledgement}

Financial support from the Romanian National Authority for Scientific Research, CNCS-UEFISCDI, Project PN-II-ID-PCE-2011-3-0893 is gratefully acknowledged. 
IJAHP Article: Mu, Saaty/A Style Guide for Paper Proposals To Be Submitted to the International Symposium of the Analytic Hierarchy Process 2014, Washington D.C., U.S.A.

\section{Key References}

Adamus, W. (2013). Motivational aspects in management of upper secondary schools, European Journal of Business and Social Sciences, Vol. 1, No. 11, pp. 31-62;

Benitez,J.,Delgado-Gàlvan,X., Izquierdo,J., Pérez-Garcia,R. (2011) Improving consistency in AHP decision-making processes. Applied Mathematics and Computation, 219(5),2432-2441

Hadad, S. (2012) The influence of brain dominance over the continuous negotiation between the student and the professor in attributing the grade, unpublished dissertation paper

Saaty, T.L. and Shang, J.S., (2011), An innovative orders-of-magnitude approach to AHP-based multi-criteria decision making: Prioritizing divergent intangible humane acts, European Journal of Operational Research, Vol. 214, No. 3, pp.703-715. 